Por : Licda. Karen Ibarra.

Encargada laboratorio de nutrición. UCIMED.

¿"Me gusta" o "No me gusta"?

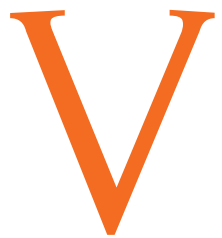

ivimos en un mundo de constante cambio, las modas vienen $y$ van, los gustos $y$ preferencias evolucionan y cambian, algunas cosas adquieren valor y otras pierden importancia. Parte de nuestra labor como nutricionistas y como profesionales en el área de salud es conocer nuestro entorno, así como las tendencias que emergen año con año y marcan los gustos y preferencias de las personas a las que brindamos un servicio; de manera que nuestra labor de educación y comunicación sea efectiva y nuestros servicios se adapten a las necesidades específicas de cada generación.

Por ejemplo, si la tendencia fuera consumir batidos, nuestra labor sería educar a las personas sobre alimentos saludables que pueden incluir en sus batidos, al mismo tiempo que se les recomienda la omisión de otros ingredientes que no representan un beneficio a su salud; hablar de postres saludables puede que sea bueno, pero no tendrá el mismo impacto que hablar de batidos saludables. Saber comunicar implica conocer a nuestro paciente o cliente, es como hablar el mismo idioma y con base en sus gustos modificar sus hábitos de forma que logre hacer cambios positivos y significativos.

Con baseenesto podemos analizarlastendenciasactuales en cuanto a alimentación, ¿Qué tipo de alimentos están “de moda"?, ¿Qué buscan las personas en su alimentación?, ¿Qué determina la alimentación de las personas?, ¿Qué factores influyen al momento de elegir un alimento y rechazar otro?, actualmente ¿Qué significa "alimento saludable" para las personas?

En un estudio realizado por la Promotora del Comercio Exterior de Costa Rica (PROCOMER) a finales del 2016 titulado “¿Hacia dónde va la industria alimentaria? Tendencias e innovaciones: prospección feria "SIAL París 2016", se identificaron 13 tendencias clasificadas en 4 ejes que muestran lo que marca actualmente el consumo de alimentos.

Referencias:

1. PROCOMER. (15 de diciembre de 2016). PROCOMER. Costa Rica exporta. (C. Medagli la industria alimentaria mundial, tomado de: www.procomer.com/es/noticias/13-tendenc 


\section{la Alimentación}

Los 4 ejes son:

1. Volver a lo básico: Se mencionan 4 tendencias:

A)-Pequeños lujos: se buscan alimentos que permiten esos momentos de indulgencia, deben verse bien por lo que el diseño importa.

B)-El producto es la estrella: productos simples con pocos ingredientes y con mínimas modificaciones.

C)-Mezclar y ensamblar: fusionar sabores, crear mezclas innovadoras, implica creatividad.

D)-Nostalgia: alimentos que permitan vincular el pasado con el presente.

2. Se mencionan 3 tendencias:

A)-Hecho en: brinda confianza en el producto, 6 de cada 10 consumidores prefieren alimentos locales.

B)- Alimentos en bruto: productos lo menos procesados posibles, llamados "raw food".

C)-Naturalmente beneficioso: se incluyen los súper alimentos y productos que por sí mismos representen un beneficio a la salud.

3. Sostenibilidad: Se mencionan 3 tendencias:

A)-Cero desperdicios: se buscan productos que aprovechen al máximo los alimentos y reduzcan el desperdicio.

B)-Menos empaque: productos que tengan empaques eficientes y no causen daño ambiental.

C)-Recursos y bienestar animal: se busca mantener un equilibrio humanitario con los animales y el ambiente.

4. Conectividad: Se mencionan 3 tendencias:

A)-Personalización: se buscan alimentos que el consumidor pueda mejorar y personalizar, un producto "hecho a la medida"

B)-De donde viene la comida: se busca transparencia en cuanto a la línea de producción y una trazabilidad efectiva. C)-Datos de salud: los consumidores desean conocer todo lo relativo al producto que están comprando.

Conocer los gustos y preferencias de las personas en cuanto a su alimentación nos permitirá crear opciones saludables que al mismo tiempo cumplan con las expectativas y preferencias de las personas y sean bien aceptadas. ¿Tienes alguna idea en mente? 